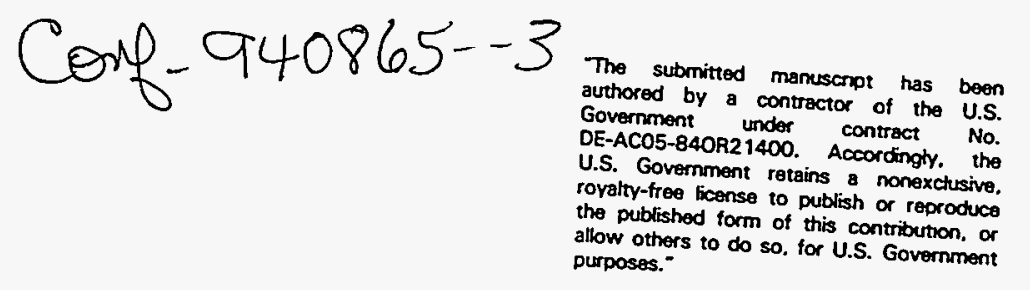

\title{
INVESTIGATION OF DEPTH-AREA RELATIONSHIPS ASSOCIATED WITH NANOINDENTATIONS*
}

\author{
L. Riester and M. K. Ferber \\ Mechanical Properties User Center \\ Oak Ridge National Laboratory \\ Oak Ridge, TN 37831-6064
}

\author{
RECEIVED \\ SEP 2319.44 \\ OSTI
}

\section{ABSTRACT}

The determination of hardness from indentation testing requires the measurement of the contact area. For indents generated at very low loads $(<20 \mathrm{mN})$ or shallow depths $(<250 \mathrm{~nm})$, optical methods do not have sufficient resolution. One approach utilized in current state-of-theart mechanical properties microprobes (MPM) involves the measurement of indenter depth during the indentation testing. Calculation of the plastic area then requires a relationship between depth and contact area. This relationship is generally derived either by assuming the indenter is perfectly sharp ("Ideal Indenter" assumption) or by calibrating the shape using materials having known hardness and elastic modulus values.

The validity of both approaches was examined by using a Scanning Force Microprobe (SFM) to measure the actual dimensions of the residual impressions made by the MPM. The SFM data revealed that the "Ideal Indenter" assumption underestimates the actual plastic area. This result accounts for the fact that hardness values measured with the MPM are typically higher than those obtained with conventional hardness testers.

\section{INTRODUCTION}

Hardness, an important property of materials, is traditionally determined by indentation testing and the measurement of the resulting contact area using optical microscopy. Often hardness needs to be measured on a very small scale, for example in the characterization of thin films, multiphase materials such as superconductors, and ion implanted surfaces. For indents generated at very low loads $(<20 \mathrm{mN})$ or shallow depths $(<250 \mathrm{~nm})$, optical methods do not

* Research sponsored in part by the U.S. Department of Energy, Asst. Sec. for Energy Efficiency and Renewable Energy, Office of Transp. Technologies, as part of the High Temperature Materials Laboratory User Program, under contract DE-AC05-84OR21400 with Martin Marietta Energy Systems, Inc. 


\section{DISCLAIMER}

This report was prepared as an account of work sponsored by an agency of the United States Government. Neither the United States Government nor any agency thereof, nor any of their employees, make any warranty, express or implied, or assumes any legal liability or responsibility for the accuracy, completeness, or usefulness of any information, apparatus, product, or process disclosed, or represents that its use would not infringe privately owned rights. Reference herein to any specific commercial product, process, or service by trade name, trademark, manufacturer, or otherwise does not necessarily constitute or imply its endorsement, recommendation, or favoring by the United States Government or any agency thereof. The views and opinions of authors expressed herein do not necessarily state or reflect those of the United States Government or any agency thereof. 


\section{DISCLAIMER}

Portions of this document may be illegible in electronic image products. Images are produced from the best available original document. 
have sufficient resolution. One approach that avoids the limitations associated with optics involves the use of a mechanical properties microprobe (MPM). The MPM shown in Fig. 1 is a special microhardness tester which operates at very low loads ( 0.02 to 12 grams). The indent is made using a three-sided (Berkovich) diamond pyramid which has a face angle of $65.3^{\circ}$ (with respect to the normal). The indenter load is generated electromagnetically and controlled by varying the current in the coil surrounding the indenter shaft. A capacitive sensor measures the indenter shaft displacement, which can be related to the contact area using the appropriate geometrical relationship for the indenter. Consequently, load and displacement can be continuously measured during the indentation process.

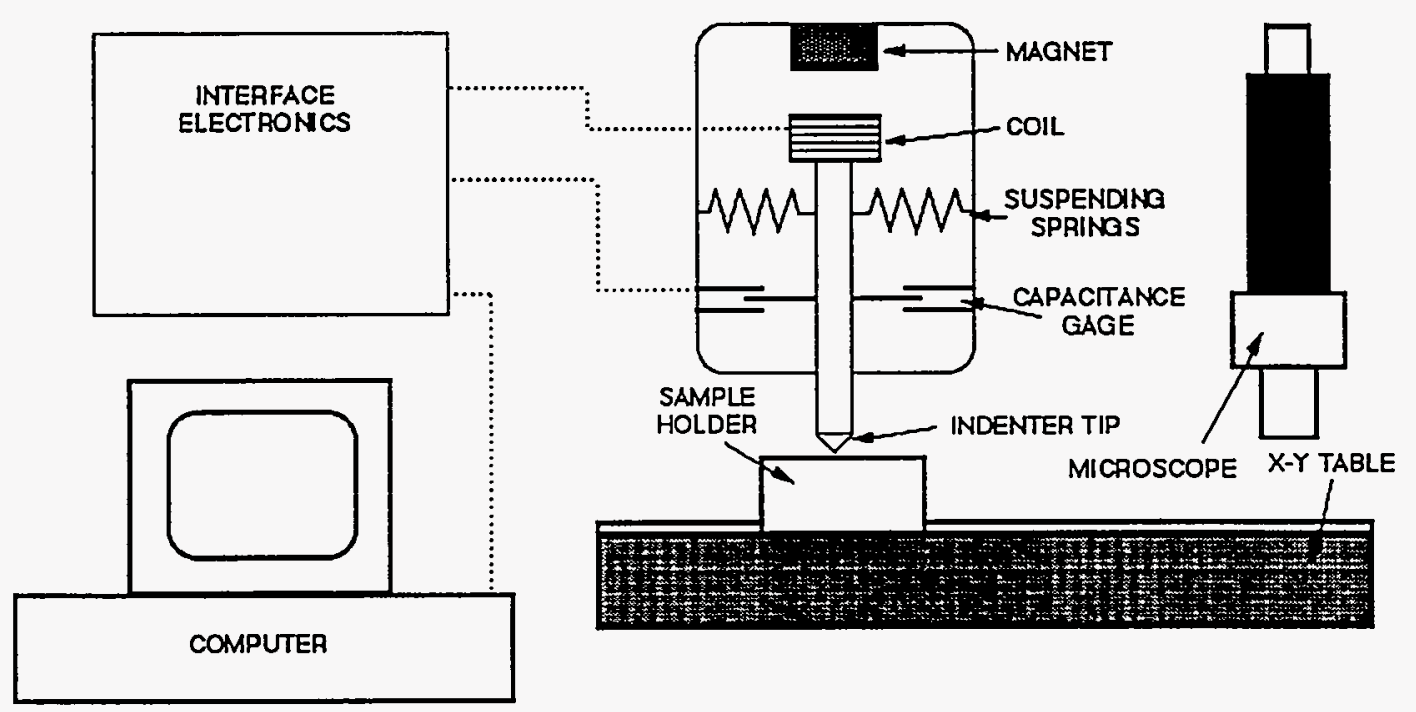

Figure 1. Schematic representation of MPM

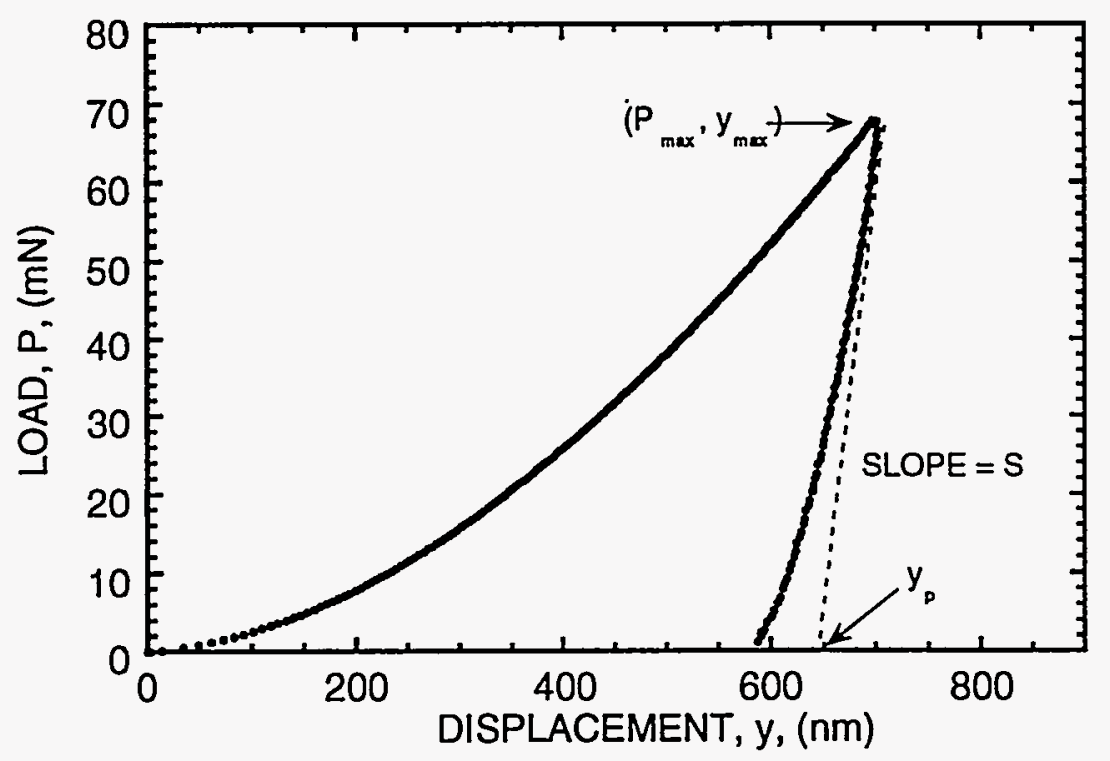

Figure 2. Typical Load/Displacement plot. $P_{\max }$ refers to maximum load, $y_{p}$ and $y_{\max }$ to plastic and maximum displacements, respectively. 
A typical load-displacement plot is shown in Fig. 2. The hardness, $\mathrm{H}$, and elastic modulus, E, are determined from this plot using the following relationships [3]:

and

$$
H=P_{\max } / A_{p}
$$

$$
\left[\left(1-v^{2}\right) / \mathrm{E}+\left(1-v_{\mathrm{i}}^{2}\right) / \mathrm{E}_{\mathrm{i}}\right]^{-1}=\mathrm{S}\left(\sqrt{\pi} / \sqrt{\mathrm{A}_{\mathrm{p}}}\right) / 2
$$

where $A_{p}$ is the plastic (projected) area of the indent, $P_{\max }$ is the maximum load, $\nu$ is Poissons ratio, and $S$ is the unloading stiffness. The subscript, i, in Eq. 2 refers to the elastic properties of the indenter. The plastic area is equal to the projected contact area at peak load, which includes an elastic component, minus the area associated with the elastic loading. Further, $A_{p}$ can be calculated from the plastic depth, $y_{p}$, which is determined by extrapolating the slope of the unloading curve at maximum load to the displacement axis (Fig. 2).

A key challenge in the calculation of both $\mathrm{H}$ and $\mathrm{E}$ is the determination of $A_{p}$ from $y_{p}$. For an ideal, (atomically sharp) indenter having a face angle of $\theta=65.3^{\circ}$, geometric considerations dictate that the displacement, $y$, is related to the projected contact area $\mathrm{A}$ via the expression

$$
\mathrm{A}=\left[9 \tan ^{2}(\theta) / \sqrt{3}\right] \mathrm{y}^{2}=24.56 \mathrm{y}^{2}
$$

In case of a non-ideal indenter $A=F(y)$ where the function $F$ must be determined experimentally.

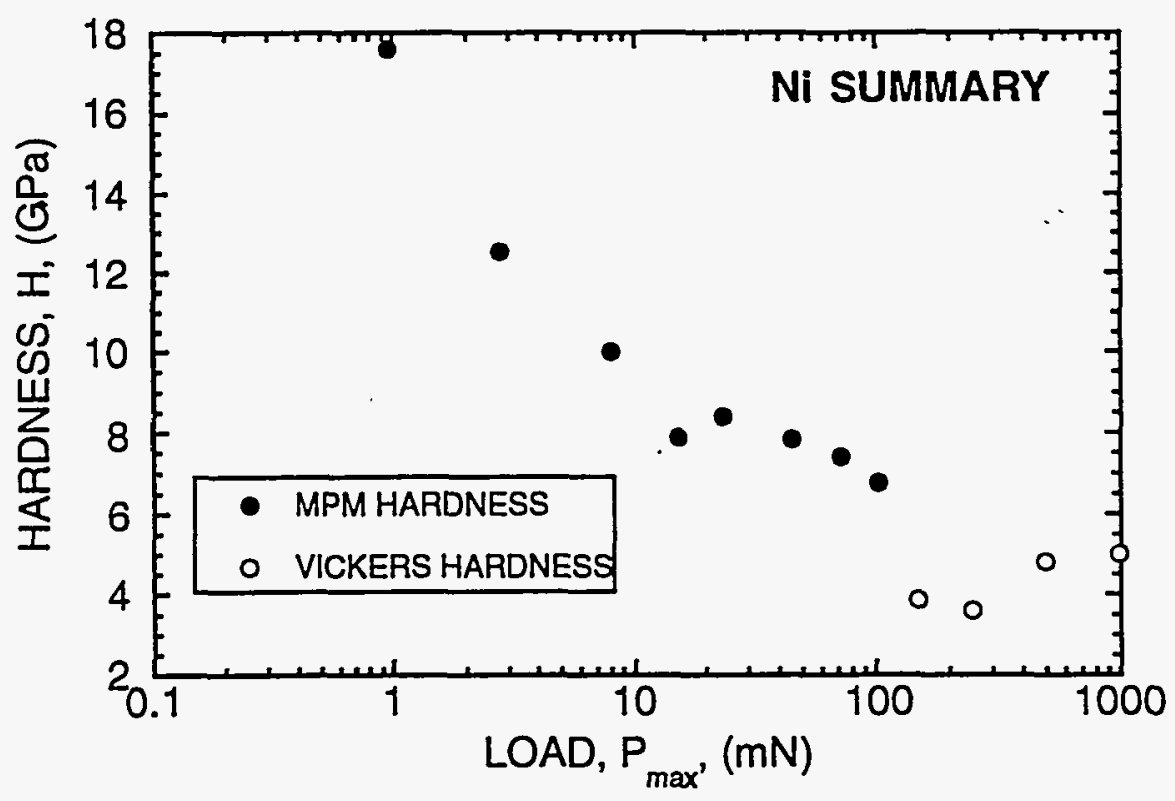

Figure 3. Comparison of MPM and Vickers hardness values measured for a Ni specimen

A major concern with data generated with the MPM is that the hardness values do not always agree with those obtained from more conventional hardness testers (Fig. 3). In a recent study by Blau, Keiser and Jackson [1], these differences were attributed to residual polishing damage and nanoscale imperfections in the indenter tip geometry. Such imperfections result in inaccuracies of the plastic area versus plastic depth $\left(A_{p}-y_{p}\right)$ relationship used in the calculation of $H$ and $E[2,3]$. Because of the limited success of optical methods for establishing this relationship, Oliver and Pharr [2] developed a procedure for indirectly determining the 
functional form of $A_{p}$ versus $y_{p}$ by assuming that the $E$ was constant for any given material and independent of depth. Standard materials with known values of $E$ were then used to develop a model procedure which could be used to adjust the area-depth relationship to yield the correct value of $E$ for any material.

In earlier experiments (unpublished data), the method of Oliver and Pharr [2] was used to generate a corrected area-depth relationship for the MPM. Figure 4 compares the corrected curve with that based on the assumption of an ideal indenter geometry $\left[A_{p}=24.56\left(y_{p}\right)^{2}\right]$. Those results indicated that area calculations using the "Ideal indenter" assumption underestimate the actual plastic area; this accounts for the higher than conventional hardness values obtained with the MPM (Fig. 3). To examine the validity of the area-depth relationship in Fig. 4, in this study the residual impressions of MPM indentations were scanned using a Scanning Force Microprobe (SFM). The SFM renders high resolution three-dimensional images of the indent areas from which estimates of $A_{p}$ may be obtained. Additionally, unlike microscopic images, SFM scans contain enhanced (1000x) height information superimposed on the $\mathrm{x}$ - and $\mathrm{y}$-axis. This seems to make the SFM particularly suitable for the study of plastic areas.

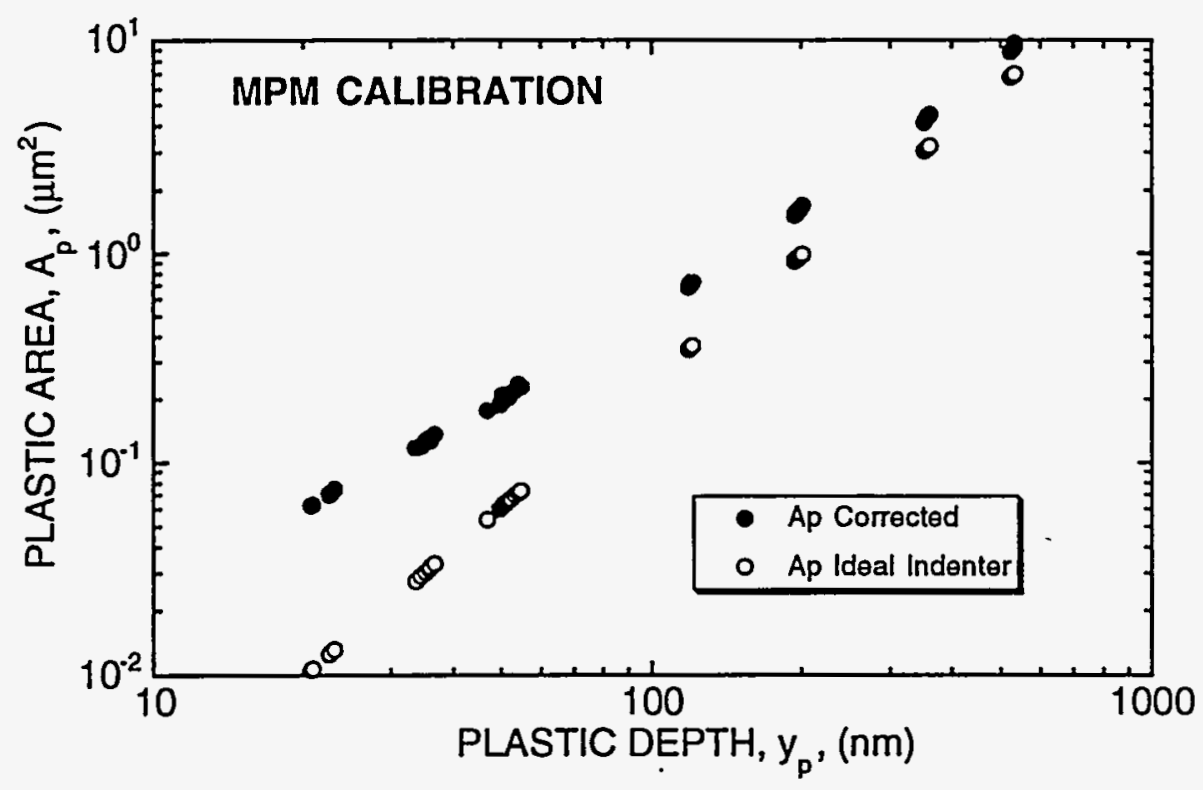

Figure 4. Comparison of the $A_{p}$ versus $y_{p}$ curve determined from the method of Oliver and Pharr [2] with that calculated from the "Ideal Indenter Geometry" expression.

\section{EXPERIMENTAL METHODS}

Samples of fused silica, aluminum, and nickel were examined in this study. The fused silica and aluminum were mechanically polished to a $0.5 \mu \mathrm{m}$ surface finish with diamond or colloidal silica, respectively. Nickel was electrodeposited on a steel substrate. A commercially available mechanical properties microprobe* equipped with a Berkovich three-sided pyramidal tip was used to make indents ranging from $100 \mathrm{~nm}$ to the maximum displacement that could be

\footnotetext{
${ }^{\star}$ Nanoindenter ${ }^{\circledR}$ manufactured by Nano Instruments, Knoxville, TN.
} 
achieved with a $12 \mathrm{~g}$ load. This resulted in measured depths between 30 and $1000 \mathrm{~nm}$ depending upon the hardness of the material. For purposes of comparison, a conventional hardness tester equipped with a Vickers indenter was used to calculate hardness.

High resolution three-dimensional images of the indentations were collected with a commercial scanning force microprobe (SFM). ${ }^{* *}$ The SFM makes high resolution threedimensional images of samples. Probe motions of $<0.1 \mathrm{~nm}$ and forces as small as $1 \mathrm{nN}$ are measurable as the probe is scanned across the sample. A laser beam is reflected from the cantilever into a four-section photodetector. When the probe moves up or down, the ratio of light intensity on the photodetectors changes, providing a signal to the system. An Everex $486 / 66 \mathrm{mhz}$ computer and Topometrix software are used to translate the signals into images. The software can be used to make length, width, depth as well as other measurements. Single line profiles can be extracted and displayed. For this study, a $5 \mu \mathrm{m} z$-Piezo scanner with a $10 \mathrm{~nm}$ diameter probe (Supertip ${ }^{\mathrm{TM}}$ ) was used. The indents were scanned at a scanning speed which allowed the probe to exit each indent with the least possible distortion.

\section{RESULTS AND DISCUSSION}

The indentations which ranged in displacement depths from 100 to $1000 \mathrm{~nm}$ yielded calculated plastic depths ranging from 50 to $1000 \mathrm{~nm}$ depending on the hardness of the material. Tables 1 and 2 provide respective summaries of the MPM and Vickers hardness measurements for all three materials. Note that the MPM hardness values were calculated using both the ideal plastic area $\left(\mathrm{H}_{\mathrm{I}}\right)$ and the corrected plastic area $\left(\mathrm{H}_{\mathrm{C}}\right)$. As shown in Fig. 5a, the uncorrected hardnesses exhibited a significant dependency upon depth and were generally much larger than the Vickers hardness numbers $\left(\mathrm{HV}_{\mathrm{V}}\right)$. However, for a given material, $\mathrm{H}_{\mathrm{C}}$ was comparable to $\mathrm{HV}$ (Fig. $5 \mathrm{~b}$ ) suggesting that the MPM calibration procedure was valid. The slight depth dependence in the $\mathrm{H}_{C}$ values was very likely a result of mechanical polishing since the same dependence is not observed in the Nickel NBS standard sample. Similar trends were also observed by Oliver and Pharr[2].

Figure 6 shows typical load-displacement curves measured for all three materials with the MPM. The slopes of the unloading curves, which is directly related to the elastic modulus, increased in the order: fused silica $(E=74 \mathrm{GPa})<$ aluminum $(\mathrm{E}=115 \mathrm{GPa})<$ nickel $(\mathrm{E}=191$ $\mathrm{GPa}$ ). These elastic recoveries caused the indent faces to close up making the measurement of depth with the SFM difficult, particularly for the fused silica. Because of the problem with the depth measurements, only the projected areas were determined using the SFM. Figures 7 and 8 include examples of the computer generated SFM images. Measuring software which allows a cursor to be applied transversely across the image for measurements and which simultaneously shows the cross section of the region being examined was used to measure the dimensions needed to calculate the area. Figure 7 illustrates that the determination of the plastic area relied upon the measurement of the height of the triangle, L. The plastic area was calculated using the expression,

$$
\mathrm{A}_{\mathrm{p}}=\mathrm{L} 2 / \sqrt{3}
$$

Note that $\mathrm{L}$ was chosen such that the plastic area was equal to the area of the impression only, with no contribution of the accumulated material surrounding the indent.

\footnotetext{
** Topometrix Explorer Scanning Force Microprobe, manufactured by Topometrix, Santa Clara, CA.
} 
Table 1: Summary of MPM Measurements.

\begin{tabular}{|c|c|c|c|c|c|}
\hline Material & $\mathrm{P}_{\max }(\mathrm{mN})$ & $\mathrm{y}_{\max }(\mathrm{nm})$ & $\mathrm{y}_{\mathbb{1}}(\mathrm{nm})$ & $\mathrm{H}_{I}(\mathrm{GPa})$ & $\mathrm{H}_{C}(\mathrm{GPa})$ \\
\hline & & & & & \\
Fused Silica & 1.88 & 97.30 & 55.39 & 49.61 & 8.29 \\
Fused Silica & 8.50 & 238.46 & 147.04 & 25.25 & 8.52 \\
Fused Silica & 27.65 & 460.03 & 313.74 & 15.95 & 7.68 \\
Fused Silica & 88.49 & 840.91 & 586.21 & 14.58 & 7.47 \\
& & & & & \\
Nickel & 2.29 & 97.13 & 81.14 & 14.23 & 5.76 \\
Nickel & 9.96 & 235.77 & 199.46 & 9.8 & 6.00 \\
Nickel & 31.01 & 456.38 & 385.67 & 7.51 & 5.98 \\
Nickel & 67.13 & 697.03 & 563.88 & 6.97 & 6.14 \\
& & & & & \\
Aluminum & 0.71 & 108.15 & 101.81 & 2.96 & 1.28 \\
Aluminum & 3.08 & 268.68 & 255.41 & 2.02 & 1.23 \\
Aluminum & 9.72 & 506.90 & 480.81 & 1.79 & 1.21 \\
Aluminum & 33.62 & 991.92 & 954.43 & 1.59 & 1.07 \\
\hline
\end{tabular}

Table 2: Summary of Vickers Measurements.

\begin{tabular}{|cccc|}
\hline Material & $\mathrm{A}_{\mathrm{p}}\left(\mu \mathrm{m}^{2}\right)$ & $\mathrm{P}_{\max }(\mathrm{mN})$ & $\mathrm{HV}(\mathrm{GPa})$ \\
\hline & & & \\
Fused Silica & 124 & 980 & 7.90 \\
Fused Silica & 254 & 1960 & 7.72 \\
Fused Silica & 628 & 4900 & 7.80 \\
& & & \\
Nickel & 171 & 980 & 5.73 \\
Nickel & 348 & 1960 & 5.63 \\
Nickel & 857 & 4900 & 5.72 \\
& & & \\
Aluminum & 800 & 980 & 1.24 \\
Aluminum & 1673 & 1960 & 1.18 \\
Aluminum & 4787 & 4900 & 1.15 \\
\hline
\end{tabular}

Line by line examination of SFM images revealed that in the case of aluminum and nickel, a substantial amount of material appeared to be accumulated around the indent. Fused silica, on the other hand, due to different plastic properties, showed no such pile up. Fig. 8 illustrates the line analysis; one line is from the flat region of the sample near an indent, the other line cuts through the center of the indent.

A comparison of results obtained by the three methods for calculating the plastic area Ap from yp for fused silica, nickel and aluminum are shown in Figs. 9, 10, and 11, respectively. The figures illustrate values of $A_{p}$ calculated from the MPM using the "ideal indenter" assumption as well as those correcting for the area-depth relationship and values for $A_{p}$ measured with the SFM. Each of these areas is plotted against the average plastic depth of the indentation. For a fixed plastic depth in each of the three materials, the MPM values of $A_{p}$ based on the corrected area-depth relationship were found to be in excellent agreement with the $S F M$ values, while $A_{p}$ based on the "ideal indenter" assumption was found to be smaller. 


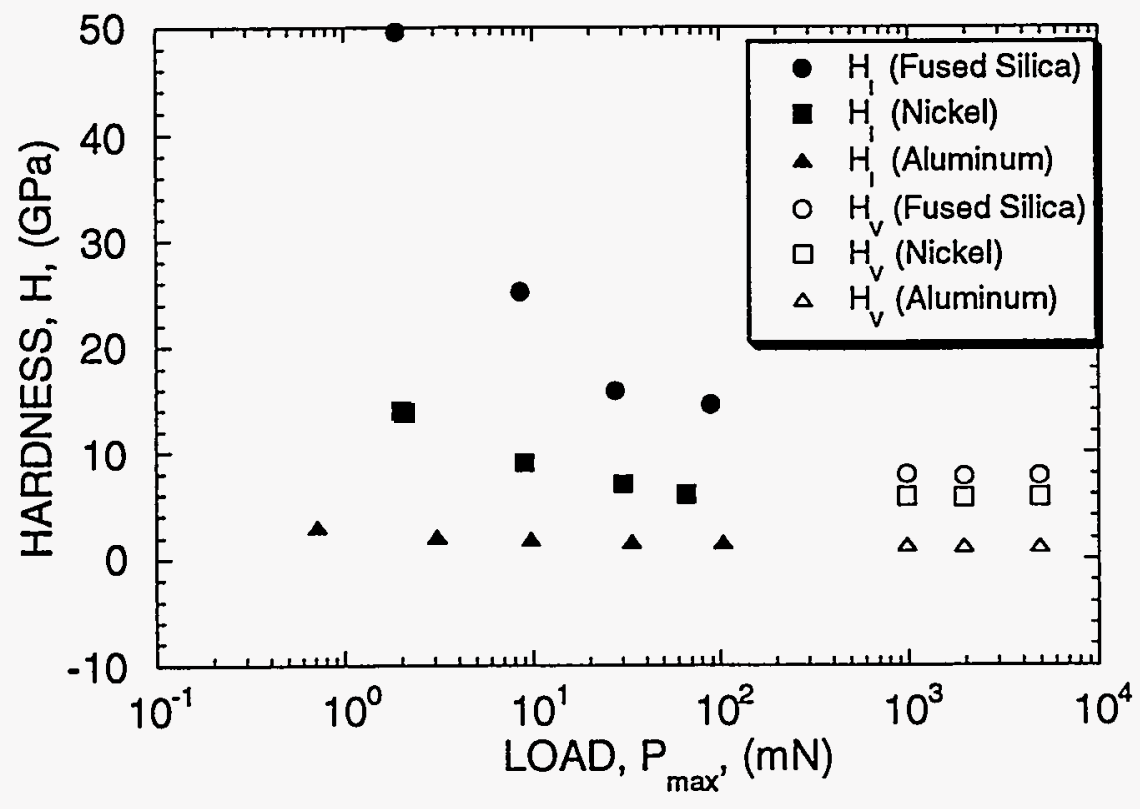

Figure 5a. Comparison of Vickers hardness measurements for fused silica, nickel and aluminum with MPM hardness values calculated using "Ideal Indenter" assumption.

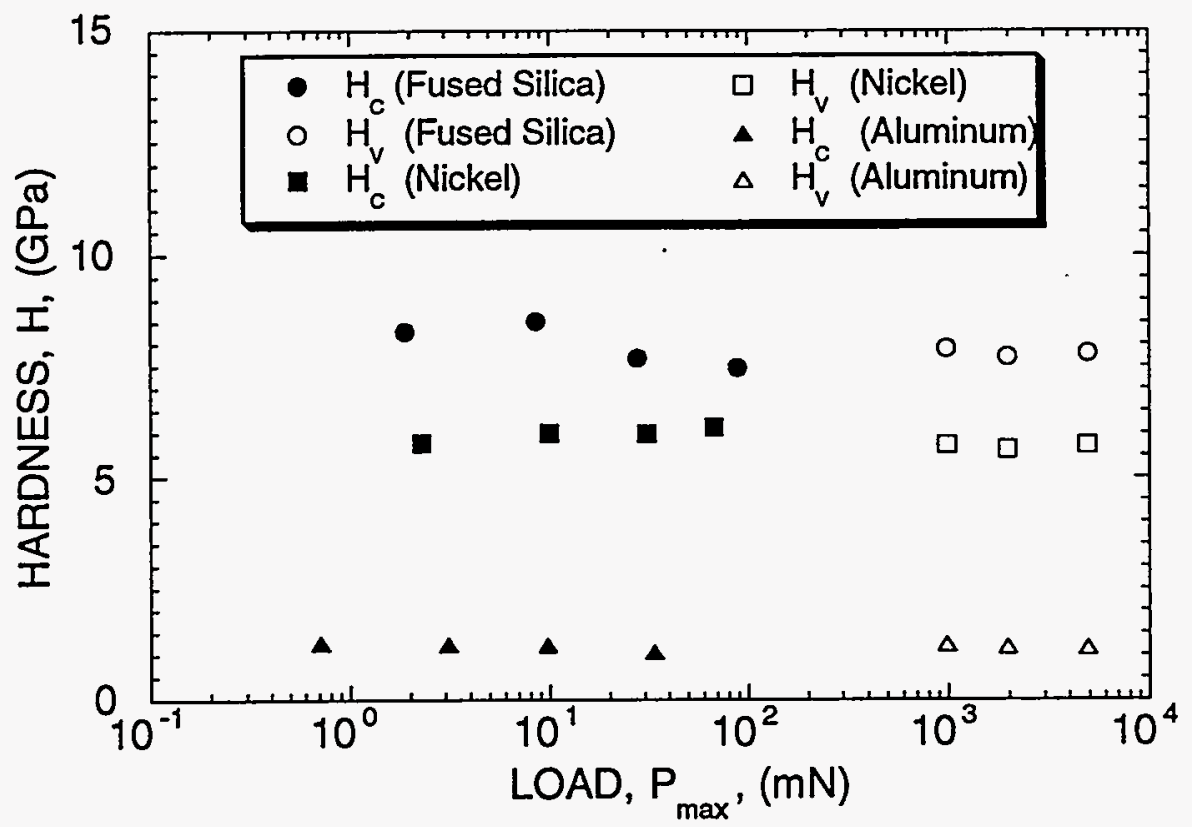

Figure 5b. Comparison of Vickers hardness measurements for fused silica, nickel and aluminum with MPM hardness values calculated using correction for plastic areas. 


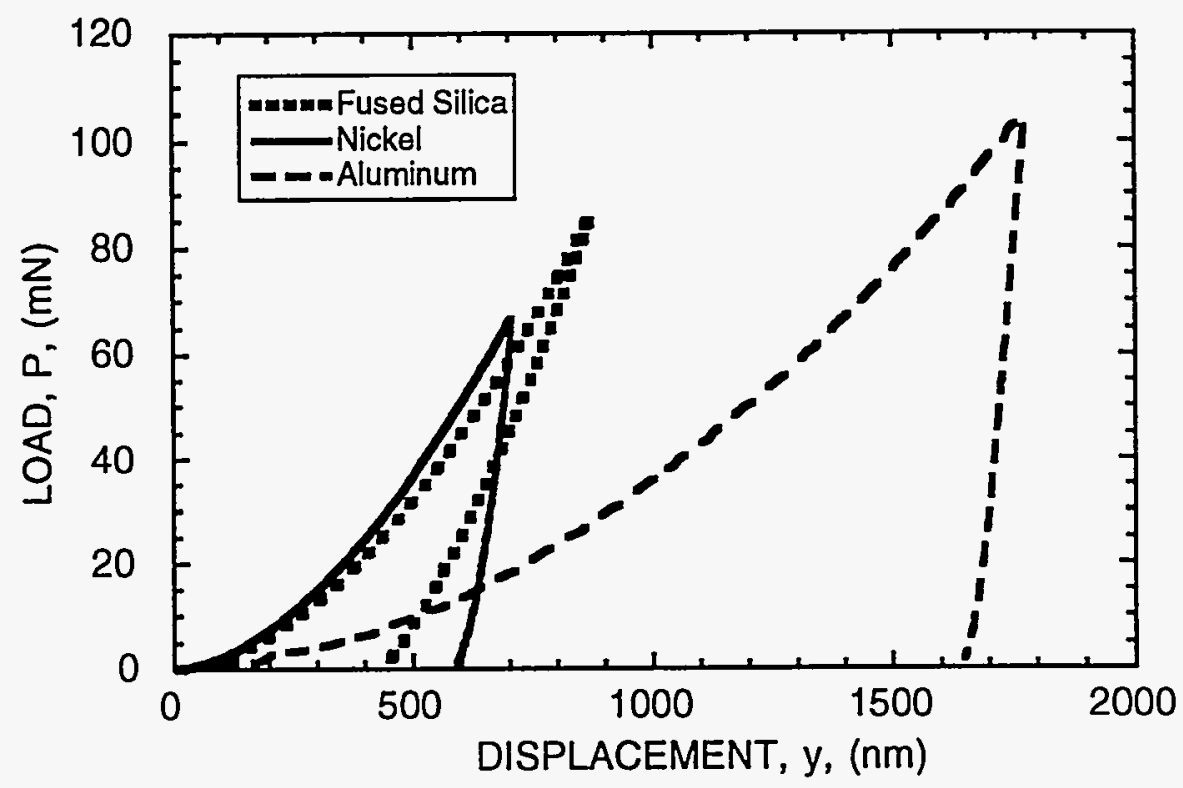

Figure 6. Load/Displacement curves for indentations in fused silica, nickel, and aluminum.
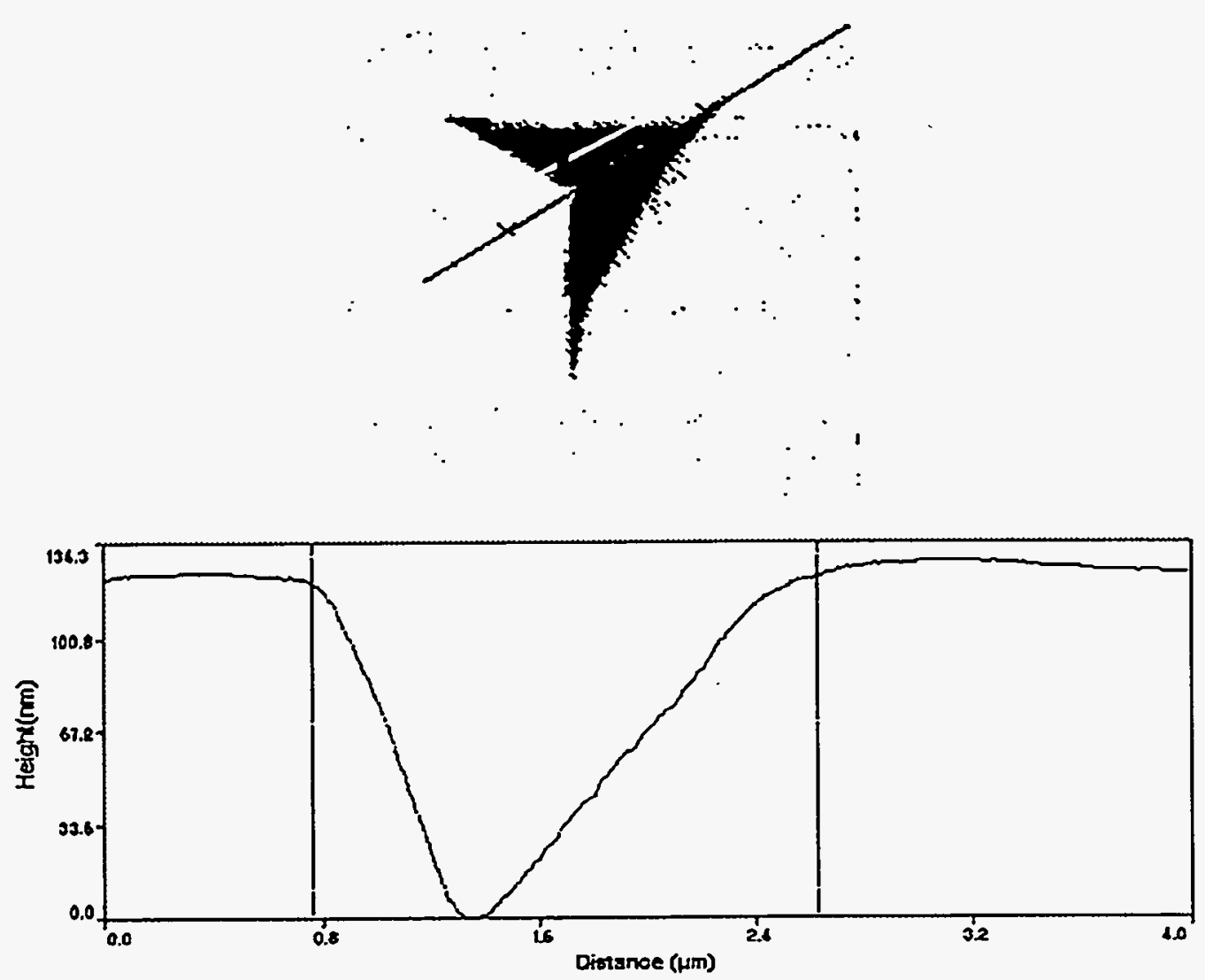

Figure 7. SFM scan of fused silica illustrating measurement of $L$. 

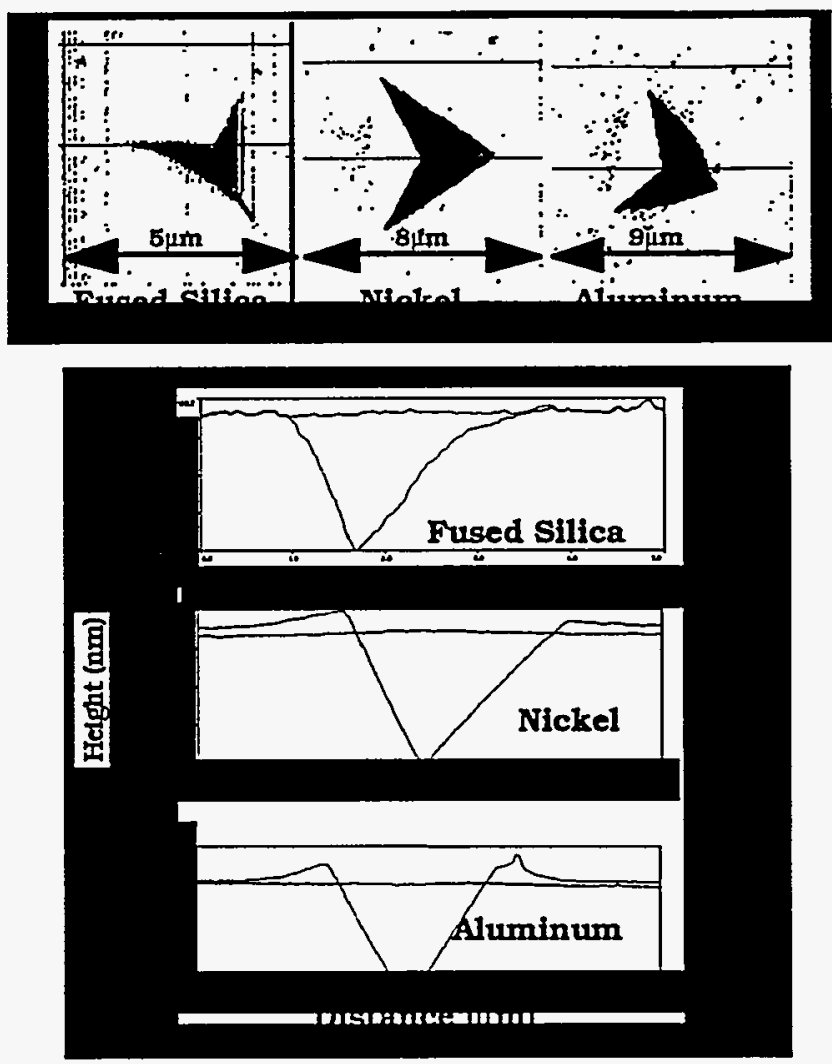

Figure 8. SFM scans of fused silica, nickel and aluminum showing horizontal profiles for definition of plastic area.

These results validate the procedure used to determine the corrected area-depth relationship for the MPM.

In addition to a visual representation of the plastic area, the SFM analysis revealed infomation about the plastic behavior during Nanoindentation. Future work will couple SFM information with mathematical modelling predictions of plastic properties of different materials in compression.

\section{SUMMARY}

The above study has shown that 3-dimensional profilometry with an SFM can be used to verify the shape of submicron indentations made with the MPM. By comparing data using the stiffness calculations based on an ideal indenter geometry and those using the corrected values to image measurements from the SFM, the model procedure developed by Oliver and Pharr [2] was verified for fused silica, nickel, and aluminum for indentations ranging in depth from 100 to $1000 \mathrm{~nm}$. The SFM was found to be uniquely suitable for detailed study of the plastic area as well as material accumulation outside the indent and regions surrounding the indent that may have sunk in. In the three-dimensional representation of a SFM scan, unlike SEM and other microscopy techniques, nanometer changes in the z-direction (height) are superimposed on an $\mathrm{X}$ - and $\mathrm{Y}$-axis in the micron scale.

Future work will include the study of indents having depths less than $100 \mu \mathrm{m}$ and greater than $1000 \mu \mathrm{m}$. The area-depth relationship also needs to be verified for brittle materials such as silicon carbide which crack during indentation. The SFM will also be used to investigate the effect of surface preparation on the plastic area of indentations. 


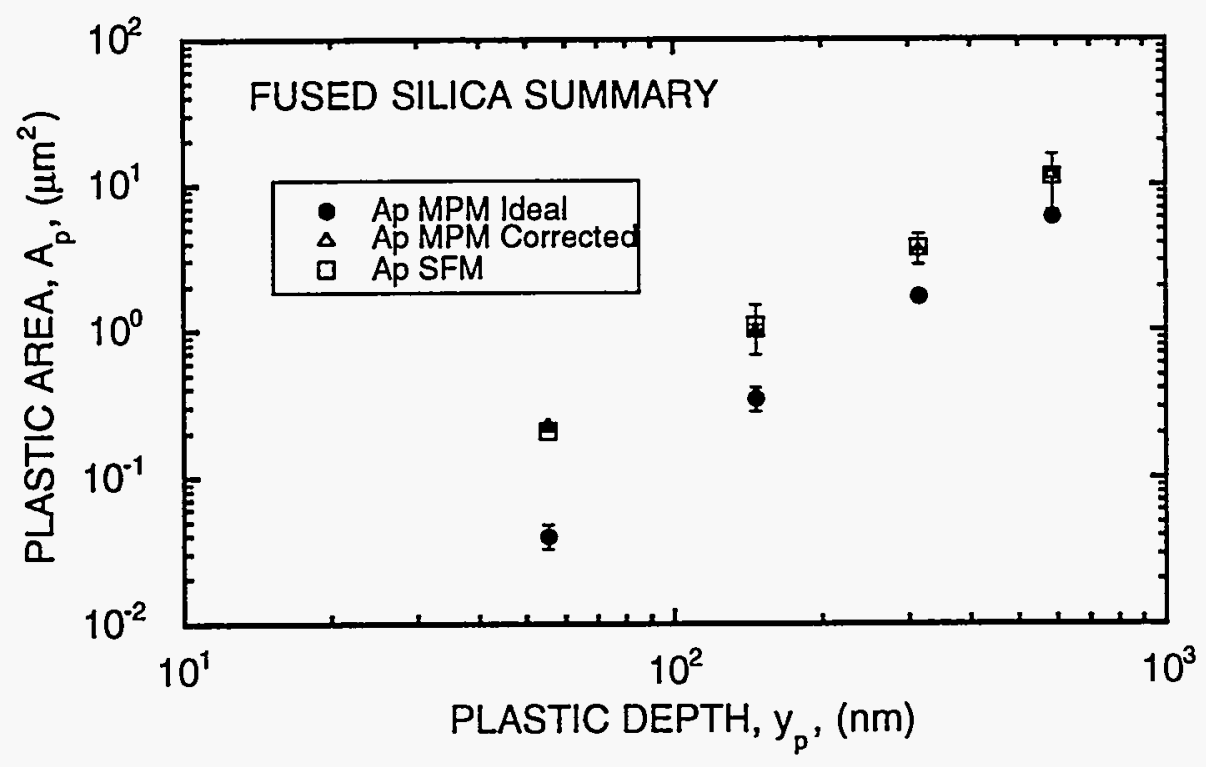

Figure 9. Depth dependence of the plastic area as calculated from the MPM Load/Displacement data and measured directly from the SFM on a fused silica specimen. The $A_{p}$ values associated with the MPM were calculated using both the "Ideal Indenter" geometry and the corrected area-depth relationship established from the method of Oliver and Pharr [2].

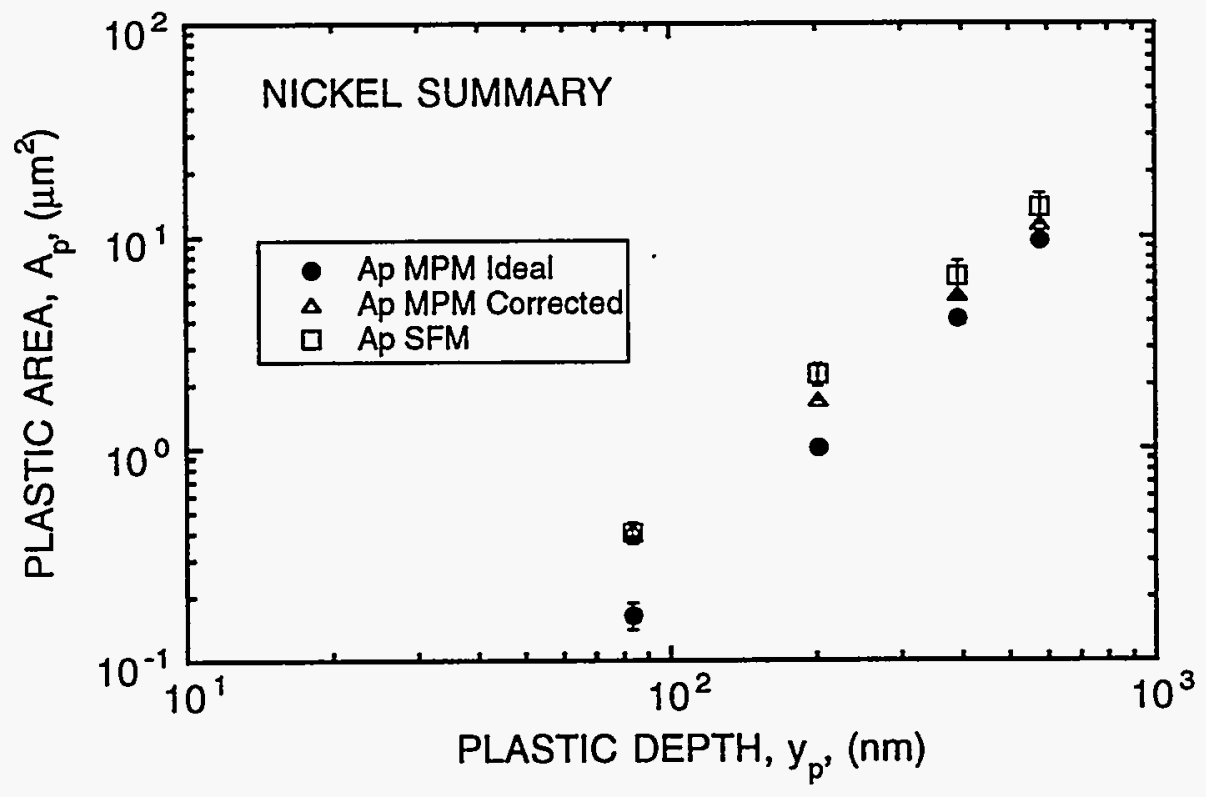

Figure 10. Depth dependence of the plastic area as calculated from the MPM Load/Displacement data and measured directly from the SFM on a nickel specimen. The $A_{p}$ values associated with the MPM were calculated as in Fig. 9. 


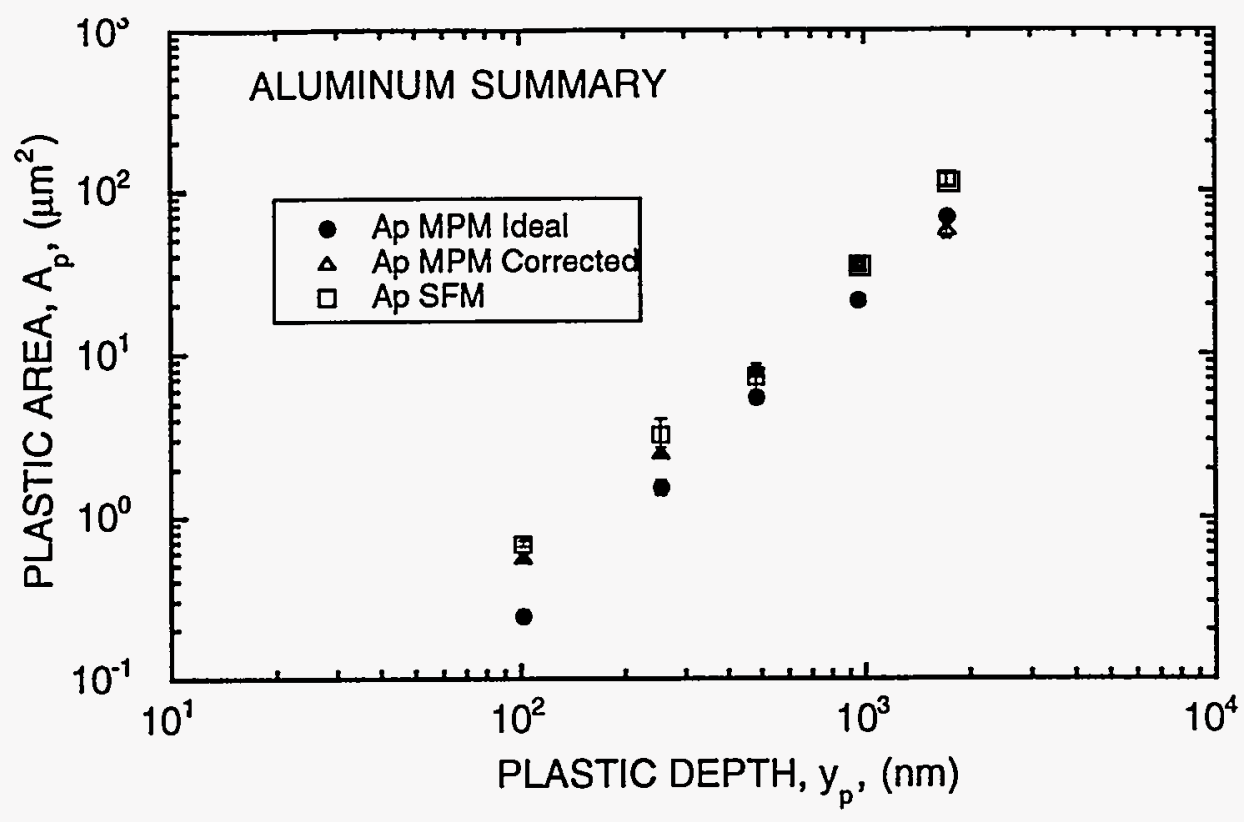

Figure 11. Depth dependence of the plastic area as calculated from the MPM Load/Displacement data and measured directly from the SFM on an aluminum specimen. The $A_{p}$ values associated with the MPM were calculated as in Fig. 9.

\section{REFERENCES}

(1) P. J. Blau, J. R. Keiser, and R. L. Jackson, Materials Characterization 30 287-293 (1993).

(2) W. C. Oliver and G. M. Pharr, J. Mater. Res., 7 [6] 1564-1583 (1992).

(3) M. F. Doerner and W. D. Nix, J. Mater. Res. 1 [4] 601-609 (1986). 


\section{LIST OF FIGURES}

Figure 1. Schematic Representation of MPM.

Figure. 2. Typical Load/Displacement Plot. $P_{\max }$ refers to maximum load, yp and ymax to plastic and maximum displacements, respectively.

Figure 3. Comparison of MPM and Vickers Hardness Values Measured for a Ni Specimen.

Figure 4. Comparison of the $A_{p}$ Versus $y_{p}$ Curve Determined from the Method of Oliver and Pharr [2] with that Calculated from the "Ideal Geometry" Expression.

Figure 5. Comparison of Vickers Hardness Measurements for Fused Silica, Nickel, and Aluminum with MPM Hardness Values Calculated using both Ideal and Corrected Plastic Areas.

Figure 6 . Load/Displacement Curves for Indentations in Fused Silica, Nickel, and Aluminum.

Figure 7. SFM Scan of Fused Silica Illustrating Measurement of L.

Figure 8. SFM Scans of Fused Silica, Nickel and Aluminum Showing Horizontal Profiles for Definition of Plastic Area.

Figure 9 Depth Dependence of the Plastic Area as Calculated from the MPM Load-Displacement Data and Measured Directly from the SFM on a Fused Silica Specimen. The $A_{p}$ values associated with the MPM were calculated using both the "Ideal Indenter" geometry and the corrected area-depth relationship established from the method of Oliver and Pharr [2].

Figure 10. Depth Dependence of the Plastic Area as Calculated from the MPM Load-Displacement Data and Measured Directly from the SFM on a Nickel Specimen. The $A_{p}$ values associated with the MPM were calculated as in Fig. 9.

Figure 11. Depth Dependence of the Plastic Area as Calculated from the MPM Load-Displacement Data and Measured Directly from the SFM on an Aluminum Specimen. The $A_{p}$ values associated with the MPM were calculated as in Fig. 9. 